\title{
Osteopromotion With Synthetic Oligopeptide-Coated Bovine Bone Mineral In Vivo
}

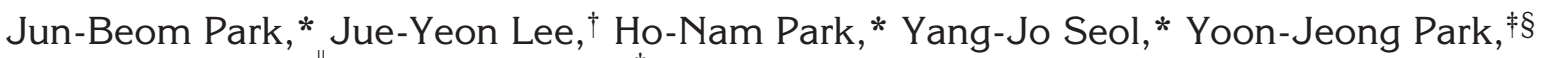
Sang-Hoon Rhee,\| Sang-Cheol Lee, ${ }^{\dagger}$ Kyoung-Hwa Kim, * Tae-Il Kim, ${ }^{*}$ Yong-Moo Lee, * Young Ku, *§ In-Chul Rhyu, * Soo-Boo Han, * and Chong-Pyoung Chung*§

Background: Recombinant human bone morphogenetic protein (rhBMP)-2 has been shown to stimulate significant regeneration of alveolar bone and cementum in periodontal defects clinically. The aim of this study was to evaluate the osteopromotive effect of oligopeptide domain-coated bovine bone mineral granules in a rabbit calvarial defect model.

Methods: The peptide-coated bovine bone was fabricated by incubating the graft material in a solution of oligopeptide domain. The cell attachment and proliferation were measured in vitro. Peptide-coated (test group) or uncoated (control group) bone minerals were implanted into $10-\mathrm{mm}$ calvarial defects in rabbits, and the animals were sacrificed at 1,2 , or 4 weeks post-surgery.

Results: The cells grown with peptide-coated bone showed significantly higher proliferation activity at all times compared to cells grown with peptide-uncoated bone mineral. At 2 weeks post-surgery, the control wounds showed a limited amount of osteoid formation in a centripetal pattern around the grafted bone, but the oligopeptide domain-coated grafted bone had formed new bone around the grafted area. At 4 weeks post-surgery, the control sites showed increased new bone formation, but they still showed a significant difference from the peptide-coated bone-implanted sites.

Conclusions: At 2 and 4 weeks, accelerated new bone formation was observed within the experimental sites compared to control groups. The use of deproteinized bovine bone combined with a synthetic oligopeptide seems to be a more beneficial material for bone regeneration in the early healing period. J Periodontol 2007;78:157-163.

\section{KEY WORDS}

Bone; bone morphogenetic protein 2; bovine; oligopeptide.

\footnotetext{
* Department of Periodontology, School of Dentistry, Seoul National University, Seoul, Korea.

$\dagger$ Nano-Intelligent Bioengineering Corporation, Seoul, Korea.

‡ Department of Craniomaxillofacial Reconstructive Sciences, School of Dentistry, Seoul National University.

$\S$ Intellectual Biointerface Engineering Center, Korea Science and Engineering Foundation, Seoul, Korea.

|| Department of Dental Biomaterials Science, School of Dentistry, Seoul National University.
}

$\mathrm{R}$ ecombinant human bone morphogenetic protein (rhBMP)-2 has been shown to stimulate clinically significant regeneration of alveolar bone and cementum in periodontal defects. ${ }^{1-5}$ The treatment of intrabony defects with BMPs is likely to require a carrier that can deliver the appropriate temporal release of a particular BMP and one that can serve as a template for new tissue formation. ${ }^{6}$ No BMPs have demonstrated periodontal regeneration in human trials.

Thus, development of the peptide mimicry of proteins has become of interest. The small amino acid sequence is as effective as its larger protein counterparts for cell adhesion, cell proliferation, and bone regeneration. A peptide sequence corresponding to the cell-binding domain of collagen was demonstrated to be involved in the binding of cells, particularly fibroblasts and osteoblasts. ${ }^{7}$ Studies by Bhatnagar et al. ${ }^{8,9}$ examined the structure of collagen and identified a potent cell-binding domain of human type 1 collagen in the $\alpha 1(\mathrm{I})$ chain sequence, ${ }^{766}$ GTPGPQGIAGQRGVV ${ }^{780}$ (P-15). Also, previous studies showed that an anorganic bone mineral particle coated with P-15 peptides can mimic the bone matrix components and facilitate bone regeneration. ${ }^{10,11}$ Suzuki et al. ${ }^{12}$ reported that ectopic bone formation was observed in 
an alginate hydrogel linked with BMP-2-derived oligopeptide.

In this study, the oligopeptide sequence with 15 amino acids, corresponding to the BMP receptor I (BMPRI)- and receptor II (BMPRII)-binding domains, was coated on the deproteinized bovine bone granules. ${ }^{13}$ The aim of this study was to evaluate the osteopromotive effect of peptide-coated bone in a rabbit calvarial defect model.

\section{MATERIALS AND METHODS}

\section{Preparation of Peptide-}

\section{Coated Deproteinized}

\section{Bovine Bone}

A peptide sequence corresponding to the cell-binding domains of BMPRI and BMPRII, containing sequence DWIVA, was from Nano-Intelligent Bioengineering Corporation (NIBEC). The peptide was synthesized chemically using an automatic peptide synthesizer" at NIBEC. The peptide was modified further at its $\mathrm{N}$-terminal with a spacer to facilitate the coating of the bone material with the peptide.

Deproteinized cancellous bovine bone particulates $^{\#}$ (0.2 to $1.00 \mathrm{~mm}$ ) were used. The peptide was applied to the bone minerals by incubating the bone for 24 hours in a solution containing the peptide in phosphate-buffered saline (PBS). The incubation was carried out at room temperature with gentle shaking to ensure equilibration of the peptide with all exposed surfaces of the microporous bovine bone. Following incubation, the bone mineral was washed three times by shaking with a $5 \times$ volume of PBS over a 24 -hour period to remove unadsorbed peptide. The bone mineral was collected, dried, and sterilized by $\gamma$-irradiation.

\section{Cell Attachment and Proliferation on \\ Peptide-Loaded Bone Mineral}

The preosteoblastic cells (MC3T3-E1) were used to evaluate the cell adhesion activity of the peptideloaded bone mineral. The suspended cell culture was applied onto peptide-coated bone mineral granules or granules without peptides for 2 hours, followed by observation with confocal microscopy. The cells attached to the granules were fixed, permeabilized, and their nuclei were stained with Hoechst 33342 reagent for ease of quantitative observation. The nuclei of the cells attached to the surface of the bone mineral were observed by confocal microscopy. Cell proliferation on the bone mineral granules coated with the peptides was measured after $1,7,14$, and 21 days

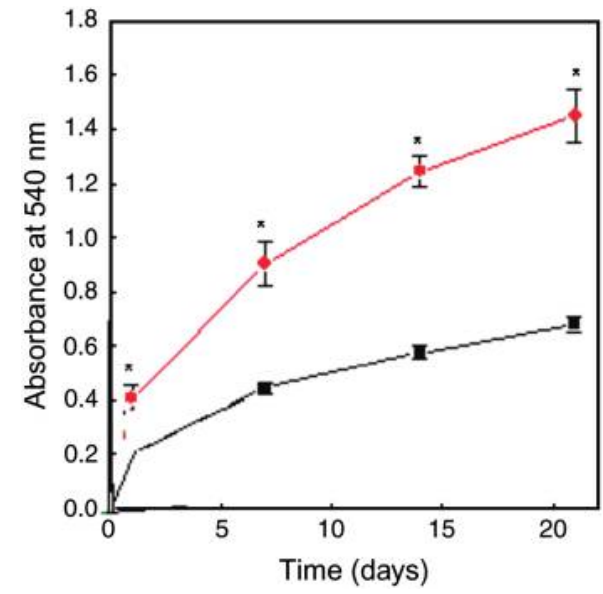

Figure 2.

Effect of peptide-loaded bone mineral on cell proliferation. After I, 7, 14 , and 21 days, cultured cells were treated with methyl thiazol2-yl-2,5-diphenyltetrazolium bromide (MTT) and incubated for 4 hours. The cells were lysed and used for measurement of absorbance of solubilized MTT in the culture medium. The bone granules without peptides served as a reference for normalization in each experiment. $\mathbf{v}=$ bone mineral; $\mathbf{O}=$ peptide-loaded bone mineral. Data are presented as mean \pm SE, and triplicate experiments were performed $(N=4)$. *P $<0.05$ compared to the granules without peptide at the same time point.

of culture. In brief, cells detached from the granules were stained with methyl thiazol-2-yl-2,5-diphenyltetrazolium bromide (MTT) and lysed for detection of the level of solubilized MTT. The absorbance of MTT

I APEC 396, Advanced ChemTech, Louisville, KY. \# OCS-B, NIBEC, Seoul, Korea. 
in cells from granules without peptide served as the reference in each experiment.

\section{Surgical Procedure}

The animal research protocol was approved by the Institute of Laboratory Animal Resources, Seoul National University. Twelve mature New Zealand white rabbits were used for the experiments. The animals were anesthetized with an intramuscular injection of xylazine and ketamine $(3.5 \mathrm{mg} / \mathrm{kg}$ body weight). After the surgical site was disinfected with betadine, local anesthesia was provided using a $2 \%$ lidocaine solution.
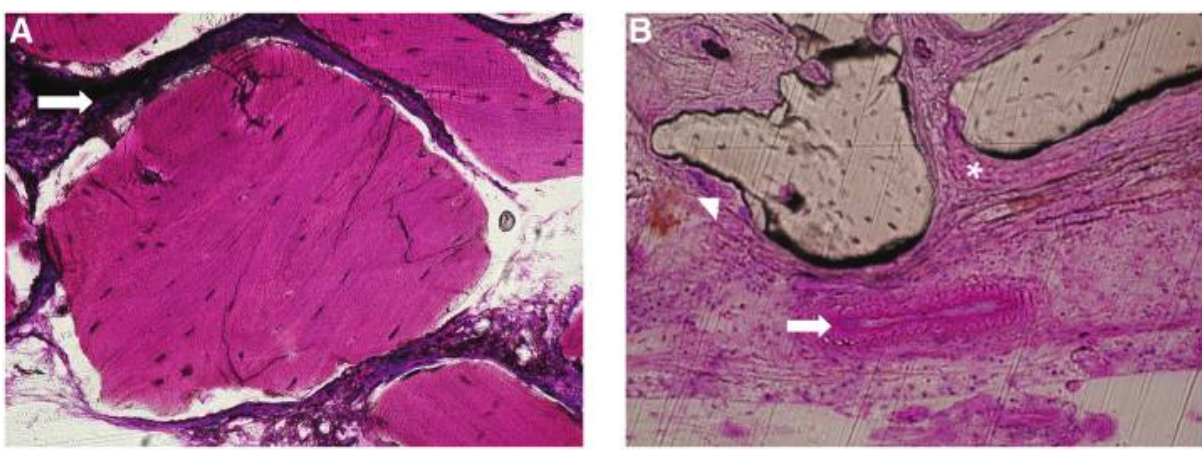

Figure 3.

A) Histologic view of non-coated bone mineral at I week. A very limited amount of immature osteoid formation around the graft material is noted (arrow). B) Histologic view of peptide-coated bone mineral at I week. Osteoid formation was noted around the graft material (*). New vessels were seen near the center of the defect (arrow), and osteoclastic activity was found adjacent to the graft material (arrowhead), making the surface of the graft material irregular. (Multiple staining; original magnification: $A$ and $B, \times 200$.)
Incisions were made, and the periosteal flaps were reflected. The external cortical plates were removed carefully using an 8-mm trephine bur with saline irrigation. Two symmetrical defects were made in each rabbit. Extreme care was taken to avoid injury to the brain. The peptide-coated bone was implanted into the defects. The peptide-uncoated bone was placed as the control. The periosteum and skin were closed using 5-0 chromic gut and 4-0 silk sutures, respectively.

\section{Histologic Preparation and Histomorphometric Evaluation}

The animals were sacrificed at 1, 2, or 4 weeks following surgery. The retrieved specimens were fixed in a $10 \%$ neutral buffered formalin solution, dehydrated through a series of ethanol solutions of increasing concentrations, and embedded in embedding media. ** Coronal sections were sliced, ground, ${ }^{\dagger \dagger}$ and stained with multiple staining (basic fuchsin and toluidine blue methods). Microscopic examination was conducted using a light microscope. ${ }^{\ddagger}$

After microscopic examination, a photograph of each slide was taken using a digital camera, $\$ \S$ and the resulting images were saved on a computer. Computer-assisted histomorphometric measurements of the newly formed bone were obtained using an automated image analysis system.|l|| The ratio of bone regeneration was calculated as the area of newly formed bone divided by that of the original defects.

\section{Statistical Analysis}

Statistical analysis was performed using statistical software. IfI Data were reported as mean \pm SD with a significance level of $P<0.05$. Analysis of variance was performed to compare cell proliferation data. A paired Student $t$ test was used to compare data from the in vivo histomorphometric analysis.
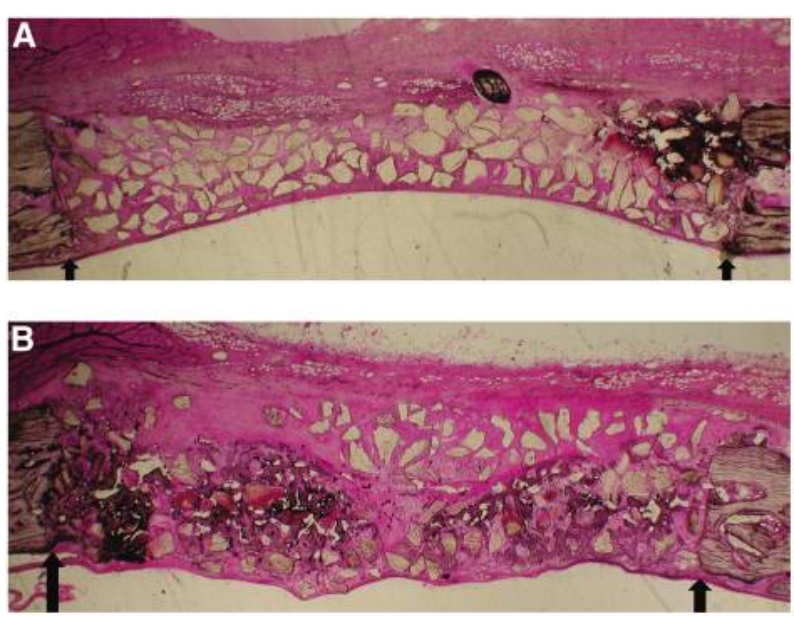

Figure 4.

A) Histologic view of non-coated bone mineral specimen after 2 weeks. Newly formed bone with osteocytes was evident at the periphery of defects, but less bone formation activity was noted in the central aspects of the defects. The bony margin is indicated by an arrow. B) Histologic view of peptide-coated bone mineral specimen after 2 weeks. New bone and osteoid formation was more obvious, and the defect tended to coalesce with the new bone. The bony margin is indicated by an arrow. (Multiple staining; original magnification: $A$ and $B, \times 12.5$.)

\section{RESULTS}

\section{Cell Attachment and Proliferation on Peptide-Loaded Bone Mineral}

Culture plates without surface modification were used in this experiment to prevent non-specific cell

\footnotetext{
** Technovit 7200, Exakt, Hamburg, Germany.

$\dagger \dagger$ Exakt.

㭋 Olympus BH-2, Olympus Optical, Osaka, Japan.

$\S \S$ Olympus Optical.

III TDI Scope Eye, Seoul, Korea.

ๆf SPSS v10.1, SPSS, Chicago, IL.
} 
attachment. The cell attachment of the bone mineral without peptide was not as significant as that of peptide-coated bone mineral. The nuclei of cells attached around the surface of bone mineral were more obvious than those of cells attached to bone mineral without peptides (Fig. 1). A large amount of cell coverage was observed on the surface of the peptideloaded bone mineral compared to that without peptide. In addition, the peptide-coated bone mineral enhanced cell proliferation for 21 days (Fig. 2).

\section{Histologic Evaluation of Bone Regeneration in Rabbit Calvarial Defects}

No specimen revealed any evidence of infection or foreign body reaction, and all wounds showed a good healing response. At 1 week post-surgery, the defect area was occupied mainly by graft particles and connective tissue. The control side showed little evidence of osteoid formation around the bone (Fig. 3A). However, the experimental specimens showed many small vessels near the center of the defect, indicating higher cellular activity. Evidence of osteoid formation adjacent to the graft material could be found. The osteoclast-like cells, which are multinucleated cells, were sitting on the graft bone, making its surface irregular (Fig. 3B).

At 2 weeks post-surgery, the ratio of the area occupied by the graft particles was reduced in the control specimens. The specimens showed a limited amount of new osteoid and bone formation developing in a centripetal manner or adjacent to the graft material (Figs. 4A and 5A). In the experimental specimens, new bone formation was more obvious around the grafted material, and the defect tended to coalesce with new bone, which could be seen clearly at high power (Figs. 4B and 5B).

At 4 weeks, the quantity of new bone was greater than that observed at 2 weeks in both groups. The new bone was deposited evenly around the graft material, the bone mineral was integrated fully with the new bone, and a more advanced stage of remodeling and consolidation was noted in both groups (Figs. 6 and 7). The control sites showed increased new bone formation compared to the 2-week control specimens, but they still showed a significant difference from the experimental test sites.

\section{Histomorphometric Evaluation of Calvarial Defects}

The results of the histomorphometric analysis are shown in Table 1 . The average area occupied by
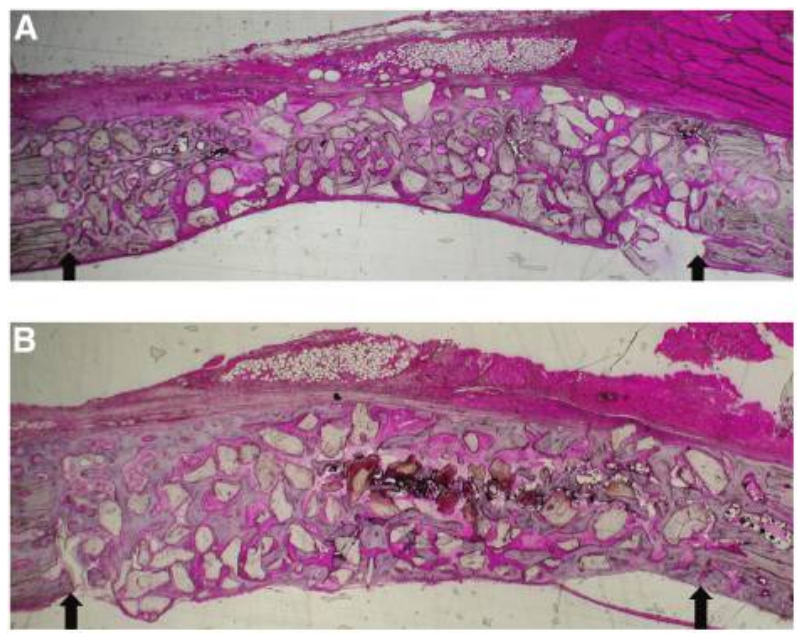

Figure 6.

A) Histologic view of non-coated bone mineral specimen after 4 weeks. New bone formation was noted all over the defect area. The bony margin is indicated by the arrow. B) Histologic view of peptide-coated bone mineral specimen after 4 weeks. The bony margin is indicated by the arrow. (Multiple staining; original magnification: $A$ and $B, \times 12.5$.)

new bone was $6.60 \% \pm 0.89 \%$ for the control site and $23.72 \% \pm 1.73 \%$ for the experimental site at 2 weeks. At 4 weeks, the average area was $34.77 \% \pm$ $3.31 \%$ and $42.27 \% \pm 2.35 \%$, respectively. There were significant differences in the regenerated areas between control and experimental sites at 2 and 4 weeks. The values at 4 weeks were significantly different from those at 2 weeks in both groups.

\section{DISCUSSION}

Bone regeneration has become a significant area of research. As a result of emerging activity in this field, a new class of drugs has been introduced with excellent potential to stimulate bone formation and 

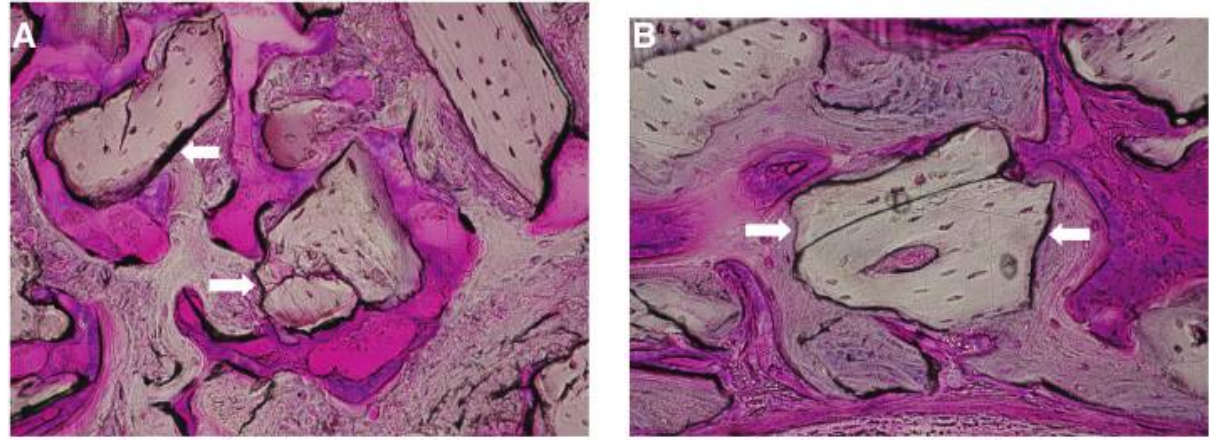

Figure 7.

A) Higher magnification of selected site from Figure 6A. The graft was integrated fully with the new bone (arrow). B) Higher magnification of selected site from Figure 6B. The grafted bone was integrated fully with the new bone and a more advanced stage of remodeling and consolidation was noted (arrow). (Multiple staining; original magnification: A and B, $\times 200$.)

has been identified as a cellbinding domain for mesenchymal progenitor cells. ${ }^{8}$ A synthetic 15 -amino acid sequence (P-15), with steric similarities to the cell-binding site of type I collagen, was demonstrated to promote cell adhesion, facilitate physiological processes in a manner similar to collagen, and promote cell differentiation. ${ }^{9,20,21} \mathrm{P}-15$, associated with anorganic-derived bone matrix, was helpful in the treatment of periodontal defects and alveolar ridge defects and in sinus-lifting procedures. ${ }^{10,22-25}$

A synthetic peptide, corre-

Table I.

Induced Bone Formation (ratio of the area of newly formed bone to original defect)

\begin{tabular}{|c|c|c|}
\hline Group & 2 Weeks & 4 Weeks \\
\hline Non-coated bone & $6.60 \% \pm 0.89 \%$ & $34.77 \% \pm 3.31 \% *$ \\
\hline Peptide-coated bone & $23.72 \% \pm 1.73 \% \dagger$ & $42.27 \% \pm 2.35 \%$ * \\
\hline $\begin{array}{l}\text { The value at } 4 \text { weeks w } \\
\text { There was a significan } \\
\text { mineral and non-coated } \\
\text { There was a significan } \\
\text { mineral and non-coated }\end{array}$ & $\begin{array}{l}\text { significantly different } \\
\text { difference between } \\
\text { one mineral groups a } \\
\text { difference between } \\
\text { one mineral groups a }\end{array}$ & $\begin{array}{l}\text { om that at } 2 \text { weeks. } \\
\text { peptide-coated bone } \\
2 \text { weeks }(P<0.05) \text {. } \\
\text { peptide-coated bon€ } \\
\text { a weeks }(P<0.05)\end{array}$ \\
\hline
\end{tabular}

to induce the regeneration of new bone. The new class of drugs is based on protein growth factors, endogenous proteins that are effective in stimulating bone formation. ${ }^{13}$ BMPs are one example of this class of drugs; these are members of the transforming growth factor- $\beta$ superfamily and have been known to induce heterotopic bone formation. ${ }^{14}$ The pharmacokinetics of BMPs and the retention of BMPs in the implanted carrier are of crucial importance for successful bone induction. ${ }^{15} \mathrm{~A}$ clinically relevant result was obtained by increasing the concentration of BMPs. ${ }^{16,17}$ The increases in the quantity and rate of bone induction by rhBMP- 2 were affected by the delivery system and the animal species used. ${ }^{17}$ However, the optimum release pattern of BMPs has not been established; therefore, BMPs should be applied in small dosages because they have various effects. ${ }^{18}$

This unpredictability, particularly with reference to the effectiveness of the highly concentrated applied substances, has led to interest in receptor technology, which has proven to be a practical and cost-efficient method of accelerating bone regeneration. ${ }^{19} \mathrm{~A}$ short sequence of collagen $\alpha 1$ (I), forming the major proportion $(85 \%)$ of the organic components of bone, sponding to residues 68 through 87 of BMP-2, recruited osteocalcin-positive osteoblasts and induced ectopic calcification when a peptide-conjugate alginate gel was implanted into a rat's calf muscle. ${ }^{12}$ It also was found that the synthetic peptide corresponding to residues 73 though 92 of BMP-2 induced higher alkaline phosphatase activity than the 68 though 87 peptide, ${ }^{26}$ and a 73 though 92 peptide-conjugated alginate gel showed prolonged ectopic calcification for up to 7 weeks in rat calf muscle. ${ }^{27}$

A synthetic peptide domain containing the binding domains for BMPRI and BMPRII was used in this study. The peptide sequence contained wrist and knuckle epitopes and, therefore, was anticipated to mimic functions similar to the whole molecule of BMP-2. Our group documented the effect of the peptide on cellular activity and surface activation on implants under a microscopic observation. ${ }^{13}$ It was suggested that the peptidomimetics of the binding domain of BMP-2 could result in a partial role of whole BMP-2 in terms of bone cell maturation, including mineralization, thereby increasing bone healing efficacy.

In this study, the peptide was used to coat the demineralized bovine bone, and the effect of the peptide was evaluated. The attachment level on the synthetic peptide increased in a dose-dependent fashion; these results indicated that the oligopeptide domain was loaded quantitatively into bone mineral and was active in promoting cell adhesion. The peptide-loaded bone mineral enhanced cell proliferation for 21 days; it is possible to enhance cell proliferation because the peptides loaded in bone mineral are able to maintain their biologic activity for 21 days.

Histologic observation using multiple staining showed that no adverse response was induced by the graft bone, with or without peptide. The peptideloaded bone sites showed evidence of osteoid formation near the center of the defect at 1 week after 
surgery. New bone formation was more evident at the experimental site 2 weeks after surgery compared to the control site.

In the histomorphometric analysis, the percentage gain of bone regeneration was calculated as the ratio of the area of newly formed bone to that of the original defect, as reported previously by our group. ${ }^{28} \mathrm{~A}$ significant finding in this study is the accelerated formation of new bone observed within the experimental sites at 2 and 4 weeks. These results suggest that new bone formation and the normal healing process in the defects may have increased because of the synthetic oligopeptide.

The paired $t$ test $P$ values at 2 and 4 weeks were 0.006 and 0.033 , respectively, showing that the difference was more evident after 2 weeks. This suggests that the synthetic oligopeptide has more beneficial effects; deproteinized bovine bone combined with a synthetic oligopeptide seems to be a more beneficial material than uncoated bone for bone regeneration, especially in the early healing period.

\section{CONCLUSIONS}

After 2 and 4 weeks, accelerated new bone formation was observed within the experimental sites with peptide-coated bone minerals, compared to control groups. Deproteinized bovine bone combined with a synthetic oligopeptide seems to be a more beneficial material than uncoated bone for bone regeneration, especially in the early healing period.

\section{ACKNOWLEDGMENTS}

This study was supported by the Korea Science and Engineering Foundation through the Intellectual Biointerface Engineering Center, Seoul National University. The peptide used in this study was from NanoIntelligent Bioengineering Corporation. Yoon-Jeong Park, Young $\mathrm{Ku}$, and Chong-Pyoung Chung are at the Korea Science and Engineering Foundation. Jue-Yeon Lee and Sang-Cheol Lee are scientists for the Nano-Intelligent Bioengineering Corporation.

\section{REFERENCES}

1. King GN, King N, Cruchley AT, Wozney JM, Hughes FJ. Recombinant human bone morphogenetic protein-2 promotes wound healing in rat periodontal fenestration defects. J Dent Res 1997;76:1460-1470.

2. Sigurdsson TJ, Lee MB, Kubota K, Turek TJ, Wozney JM, Wikesjö UME. Periodontal repair in dogs: Recombinant human bone morphogenetic protein-2 significantly enhances periodontal regeneration. $\underline{J}$ Periodontol 1995;66:131-138.

3. Kinoshita A, Oda S, Takahashi K, Yokota S, Ishikawa I. Periodontal regeneration by application of recombinant human bone morphogenetic protein-2 to horizontal circumferential defects created by experimental periodontitis in beagle dogs. J Periodontol 1997;68: 103-109.
4. Wikesjö UME, Guglielmoni PG, Promsudthi A, et al. Periodontal repair in dogs: Effect of rhBMP-2 concentration on regeneration of alveolar bone and periodontal attachment. J Clin Periodontol 1999;26:392-400.

5. Selvig KA, Sorensen RG, Wozney JM, Wikesjö UME. Bone repair following recombinant human bone morphogenetic protein-2 stimulated periodontal regeneration. J Periodontol 2002;73:1020-1029.

6. King GN. The importance of drug delivery to optimize the effects of bone morphogenetic proteins during periodontal regeneration. Curr Pharm Biotechnol 2001; 2:131-142.

7. Seyedin SM. Osteoinduction: A report on the discovery and research of unique protein growth factors mediating bone development. Oral Surg Oral Med Oral Pathol 1989;68:527-530.

8. Bhatnagar RS, Qian JJ, Gough CA. The role in cell binding of a $\beta$-bend within the triple helical region in collagen $\alpha 1(\mathrm{I})$ chain: Structural and biological evidence for conformational tautomerism on fiber surface. J Biomol Struct Dyn 1997;14:547-560.

9. Bhatnagar RS, Qian JJ, Wedrychowska A, Sadeghi M, Wu YM, Smith N. Design of biomimetic habitats for tissue engineering with P-15, a synthetic peptide analogue of collagen. Tissue Eng 1999;5:53-65.

10. Yukna RA, Callan DP, Krauser JT, et al. Multi-center clinical evaluation of combination anorganic bovinederived hydroxyapatite matrix (ABM)/cell binding peptide ( $\mathrm{P}-15)$ as a bone replacement graft material in human periodontal osseous defects: 6-month results. J Periodontol 1998;69:655-663.

11. Yukna RA, Krauser JT, Callan DP, Evans GH, Cruz R, Martin M. Multi-center clinical comparison of combination anorganic bovine-derived hydroxyapatite matrix $(A B M) /$ cell binding peptide $(P-15)$ and $A B M$ in human periodontal osseous defects: 6 -month results. J Periodontol 2000;71:1671-1679.

12. Suzuki Y, Tanihara M, Suzuki K, Saito A, Nishimura Y. Alginate hydrogel linked with synthetic oligopeptide derived from BMP-2 allows ectopic osteoinduction in vivo. J Biomed Mater Res 2000;50:405-409.

13. Seol YJ, Park YJ, Lee SC, et al. Enhanced osteogenic promotion around dental implants with synthetic binding motif mimicking bone morphogenetic protein (BMP)-2. J Biomed Mater Res A 2006;77:599-607.

14. Trippel SB, Coutts RD, Einhorn TA, Mundy GR, Rosenfeld RG. Growth factors as therapeutic agents. J Bone Joint Surg 1996;78A:1272-1286.

15. Wozney JM, Rosen V, Celeste AJ, et al. Novel regulators of bone formation: Molecular clones and activities. Science 1988;242:1528-1534.

16. Uludag $\mathrm{H}$, Friess W, Williams D, et al. rhBMP-collagen sponges as osteoinductive devices: Effects of in vitro sponge characteristics and protein $\mathrm{pI}$ on in vivo rhBMP pharmacokinetics. AnnNYAcadSci1999;875:369-378.

17. Fiorellini JP, Howell TH, Cochran D, et al. Randomized study evaluating recombinant human bone morphogenetic protein-2 for extraction socket augmentation. J Periodontol 2005;76:605-613.

18. Govender S, Csimma C, Genant HK, et al. Recombinant human bone morphogenetic protein-2 for treatment of open tibial fractures: A prospective, controlled, randomized study of four hundred and fifty patients. JBone Joint Surg Am 2002;84-A:2123-2134.

19. Reddi AH. Role of morphogenetic proteins in skeletal tissue engineering and regeneration. Nat Biotechnol 1998; 16:247-252. 
20. Valentin AH, Weber J. Receptor technology-cell binding to P-15: A new method of regenerating bone quickly and safely - Preliminary histomorphometrical and mechanical results in sinus floor augmentation. Keio J Med 2004;53:166-171.

21. Bhatnagar RS, Qian JJ, Wedrychowska A, Dixon E, Smith N. Biomimetic habitat for cells: Ordered matrix deposition and differentiation in gingival fibroblasts cultured on hydroxyapatite coated with a collagen analogue. Cells Mater 1999;9:93-104.

22. Lallier TE, Yukna R, St. Marie S, Moses R. The putative collagen binding peptide hastens periodontal ligament cell attachment to bone replacement graft materials. J Periodontol 2001;72:990-997.

23. Krauser JT, Rohrer MD, Wallace SS. Human histologic and histomorphometric analysis comparing Osteograf/ $N$ with PepGen P-15 in the maxillary sinus elevation procedure: A case report. Implant Dent2000;9:298-302.

24. Yukna RA, Salinas TJ, Carr RF. Periodontal regeneration following use of ABM/p-15: A case report. Int J Periodontics Restorative Dent 2002;22:146-155.

25. Yukna RA, Krauser JT, Callan DP, Evans GH, Cruz R, Martin M. Thirty-six month follow-up of 25 patients treated with combination anorganic bovine-derived hydroxyapatite matrix (ABM) cell binding peptide $(P-15)$ bone replacement grafts in human infrabony defects. I. Clinical findings. J Periodontol 2002;73: 123-128.

26. Saito A, Suzuki Y, Ogata S, Ohtsuki C, Tanihara M. Activation of osteo-progenitor cells by a novel synthetic peptide derived from the bone morphogenetic protein-2 knuckle epitope. Biochim Biophys Acta 2003; 1651:60-67.

27. Saito A, Suzuki Y, Ogata S, Ohtsuki C, Tanihara M. Prolonged ectopic calcification induced by BMP-2 derived synthetic peptide. J Biomed Mater Res 2004; 70:115-121.

28. Shin SY, Park HN, Kim KH, et al. Biological evaluation of chitosan nanofiber membrane for guided bone regeneration. J Periodontol 2005;76:1778-1784.

Correspondence: Dr. Chong-Pyoung Chung, Department of Periodontology, School of Dentistry, Seoul National University, 28-2 Yongon-Dong, Chongno-Gu, Seoul 110-749, Korea. Fax: 82-2-744-0051; e-mail: jbassoonis@yahoo. co.kr.

Accepted for publication August 15, 2006. 